John Carroll University

Carroll Collected

Biology

$11-2006$

\title{
Influence of resource pulses and perennial neighbors on the establishment of an invasive annual grass in the Mojave Desert
}

Rebecca E. Drenovsky

John Carroll University, rdrenovsky@jcu.edu

J.J.James

M. A. Caird

University of California, Davis

R. L. Sheley

Follow this and additional works at: http://collected.jcu.edu/biol-facpub

Part of the Biology Commons, and the Plant Sciences Commons

\section{Recommended Citation}

Drenovsky, Rebecca E.; James, J. J.; Caird, M. A.; and Sheley, R. L., "Influence of resource pulses and perennial neighbors on the establishment of an invasive annual grass in the Mojave Desert" (2006). Biology. 27.

http://collected.jcu.edu/biol-facpub/27

This Article is brought to you for free and open access by Carroll Collected. It has been accepted for inclusion in Biology by an authorized administrator of Carroll Collected. For more information, please contact connell@jcu.edu. 
Short communication

\title{
Influence of resource pulses and perennial neighbors on the establishment of an invasive annual grass in the Mojave Desert
}

\author{
J.J. James ${ }^{\mathrm{a}, *}$, M.A. Caird ${ }^{\mathrm{b}}$, R.E. Drenovsky ${ }^{\mathrm{c}}$, R.L. Sheley ${ }^{\mathrm{a}}$ \\ ${ }^{\text {a } U S D A-A g r i c u l t u r a l ~ R e s e a r c h ~ S e r v i c e, ~ E a s t e r n ~ O r e g o n ~ A g r i c u l t u r a l ~ R e s e a r c h ~ C e n t e r, ~ 67826-A ~ H w y ~ 205, ~}$ \\ Burns, OR 97720, USA \\ ${ }^{\mathrm{b}}$ Department of Land, Air, and Water Resources; University of California; Davis, CA 95616-8627, USA \\ ${ }^{\mathrm{c} B i o l o g y}$ Department; John Carroll University; University Heights, OH 44118-4581, USA
}

\begin{abstract}
Invasion by exotic annual grasses is one of the most significant threats to arid ecosystems in the western USA. Current theories of invasibility predict plant communities become more susceptible to invasion whenever there is an increase in the amount of unused resources. The objective of this field study was to examine how resource pulses and temporal variation in resource demand by the native shrub vegetation influences establishment of the invasive annual grass Schismus arabicus. Water and nitrogen were applied as pulses in early spring, mid-spring, or continuously throughout the growing season to plots containing either Atriplex confertifolia or Atriplex parryi shrubs. The effect of resource pulses on Schismus density and biomass was highly dependent on the seasonal timing of the resource pulses and the identity of the neighbor shrub. When resource pulses coincided with high rates of resource capture and growth of the native vegetation, density and biomass of Schismus was reduced. Schismus establishment was greater under continuous resource supply compared to pulsed resource supply, likely because more soil resources were available at a shallow depth when resources were supplied at a continuous low rate. These results suggest that the establishment of invasive annual grasses in arid systems can be influenced by the magnitude and spatial distribution of resource pulses in addition to the seasonal timing of resource pulses.
\end{abstract}

(C) 2006 Elsevier Ltd. All rights reserved.

Keywords: Annual grass; Atriplex; Invasion; Resource pulses; Schismus; Weed 
Invasion by exotic annual grasses is one of the most significant threats to arid and semiarid ecosystems in the western USA (Mack, 1984; D'Antonio and Vitousek, 1992). Emerging theories of invasibility are mechanistically linked to the ability of the community to maintain low levels of essential resources (Stohlgren et al., 1999; Davis et al., 2000; Shea and Chesson, 2002). Specifically, plant communities are predicted to become more susceptible to invasion whenever there is an increase in the amount of unused resources (Davis et al., 2000). An increase in unused resource can occur if resource uptake rates by the native plant community declines or resource supply rates increase faster than the native plant community can sequester resources.

Large temporal variation in unused resources may be an important factor influencing invasibility in arid systems. Although resource availability is classically assumed to be low in these systems, resource supply rates fluctuate greatly between pulses of relatively high resource availability and inter-pulses of low resource availability (Noy-Meir, 1973; Goldberg and Novoplansky, 1997). For example, nitrogen is typically available following pulses of precipitation, which increase mineralization and nutrient supply to roots (Nye and Tinker, 1977; Fisher et al., 1987). Plant resource capture during a pulse, however, may not depend directly on the amount of resource supplied during a pulse but may instead depend on plant growth rate and demand for that resource (Jeuffroy et al., 2002; James and Richards, 2005). Thus, in arid systems large temporal variation in unused resources may occur due to the pulsed nature of resources and because the amount of resource sequestered by the native vegetation depends on when the pulse occurs in relation to plant growth rate and resource demand.

The objective of this study was to examine how resource pulses and temporal variation in resource demand by native vegetation influence establishment of the invasive annual grass, Schismus arabicus. The saltbush scrub community selected for this study is located in the northern Mojave Desert and is dominated by the shrubs Atriplex confertifolia S. Watson (Torrey \& Frémont) and Atriplex parryi S. Watson. Schismus has become a major component of the vegetation in many Mojave and Sonoran desert plant communities (Johnson et al., 1975) and is widely established in our study system. Previous research in this system has demonstrated that adult and juvenile A. confertifolia plants have higher rates of growth and resource capture in early spring (February-March) than adult and juvenile $A$. parryi plants, whereas $A$. parryi has relatively higher rates of growth and resource capture in mid spring (March-April) than $A$. confertifolia (James, 2004). Based on these temporal differences in rates of growth and resource capture between these shrubs we hypothesized that (1) when resource pulses occurred in early spring, establishment of Schismus would be lower with $A$. confertifolia neighbors than with $A$. parryi neighbors; but (2) when resource pulses occurred in mid-spring, establishment of Schismus would be lower with $A$. parryi neighbors than $A$. confertifolia neighbors. Because resource pulses briefly increase resource availability we also predicted that (3) regardless of neighbor species, Schismus establishment would be higher when resources were supplied as pulses compared to when the same amount of resources was supplied at a low rate continuously through the growing season.

The study was conducted in the Owens Valley, California, USA $\left(36^{\circ} 21.5^{\prime} \mathrm{N}, 118^{\circ} \mathrm{W}\right.$; $1087 \mathrm{~m}$ elev.). Soils are classified as Torripsamment. Annual precipitation averages $172 \mathrm{~mm}$ with the majority of precipitation falling in winter and spring as rain. During the study year (2004), crop year precipitation was $120 \mathrm{~mm}$ and only one significant $(>2 \mathrm{~mm})$ precipitation event occurred during the study period (4.2 mm, 4 April 2004). Field plots 
(36 cm dia and spaced $1 \mathrm{~m}$ apart) were installed in a common garden in winter 2003, 1 year prior to the experiment. A plastic barrier was buried $45 \mathrm{~cm}$ deep around the outside of each plot. While such a barrier was necessary to restrict lateral movement of the resource pulses and prevented root growth of non-experimental plants into the plots it is possible that these barriers could influence root growth rates of plants growing near the edge of the plot.

Treatments were applied in a complete factorial design $(2$ neighbor identity treatments $\times 2$ neighbor density treatments $\times 3$ temporal patterns of resource supply) and replicated in 7 blocks. The neighbor identity and density treatments included four month old $A$. confertifolia or A. parryi seedlings planted at a density of one or three seedlings per plot. Shrubs were planted in 2003 and allowed to grow for 1 year before resource supply treatments were applied.

During the 2004 growing season, experimental plots were randomly assigned to receive experimental resource pulses (water plus $\mathrm{N}$ ) either three times in early spring (27 February-10 March, $\sim 6 \mathrm{~d}$ intervals), three times in mid spring (22 April-6 May, $\sim 7 \mathrm{~d}$ intervals) or as a series of small pulses continuously through the growing season (27 February-10 June, approximately twice a week) using a drip-irrigation system. The same total amount of water $(25 \mathrm{~L})$ and $\mathrm{N}(330 \mathrm{mg})$ was applied to all treatments. Combined with the natural precipitation events during the study year, total water inputs were about $17 \%$ greater than the average annual precipitation. Our total water addition for each pulses was determined by the amount of water needed to uniformly distribute $\mathrm{N}$ across the plot to a depth of $\sim 45 \mathrm{~cm}$. Our total $\mathrm{N}$ addition was expected to increase soil $\mathrm{N}$ concentration to around $7 \mathrm{mg} \mathrm{kg}^{-1}$, which is within the range of the amount inorganic $\mathrm{N}$ available during natural pulses in this system (James et al. unpublished). While each experimental pulse consisted of three events, precipitation inputs in these system are generally occur as a series of precipitation events clustered over several days (Loik et al., 2004). The frequency between events within each of our experimental pulses, therefore, was probably somewhat longer than the frequency associated with natural events. Water and $\mathrm{N}$ were supplied in combination because both resources typically limit plant growth in arid systems and supply rates of $\mathrm{N}$ are generally coupled with precipitation events.

Because Schismus, which disperses easily and can form a long-lasting seed bank (Gutterman, 2003), had repeatedly established large populations in the common garden area and throughout the plant community over multiple years and seed traps show that Schismus seed flux at the site can exceed 1000 seeds $\mathrm{m}^{-2}$ month $^{-1}$ in winter and spring (Breen, 2005), natural dispersal processes and the established seed bank were used as seed sources for Schismus. Dead Schismus plants that established in 2003 were removed before the 2004 growing season so we could easily determine which plants established under the different resource pulse treatments. At the end of the 2004 growing season and following the resource pulse treatments, individual Schismus plants were counted and total Schismus biomass (dry weight) was quantified in each plot.

Effects of neighbor plant identity, neighbor plant density, and the temporal pattern of resource supply on Schismus density and biomass were analyzed by ANOVA (SAS, 2001). When assumptions of normality and homogeneity of variance were violated, data were weighted by the inverse of the variance (Neter et al., 1990). Orthogonal contrasts were used to test a priori hypotheses of treatment effects on Schismus density and biomass.

Plots planted with three shrubs had higher shrub cover $(63.4 \pm 4.9 \%)$ than plots planted with one shrub $(29.3 \pm 3.2 \%$, mean \pm SE). Analysis of variance indicated Schismus density and biomass were significantly affected by neighbor shrub density $(P<0.0001$ for density 
and $P=0.0094$ for biomass, Fig. 1a,b) as well as temporal resource supply patterns to the plots $(P=0.002$ for density and $P<0.001$ for biomass). Orthogonal contrasts indicated that under the early spring resource pulses Schismus density $(P=0.0179)$ and biomass $(P=0.0073)$ was significantly lower with $A$. confertifolia neighbors than with $A$. parryi neighbors, averaged over both neighbor density treatments (Fig. 1a, b). Contrasts suggest that there were no significant differences in Schismus density or biomass between A. confertifolia and $A$. parryi neighbors following the mid-spring pulse when averaged over both neighbor density treatments $(P>0.05)$. Averaged across the early and mid-spring

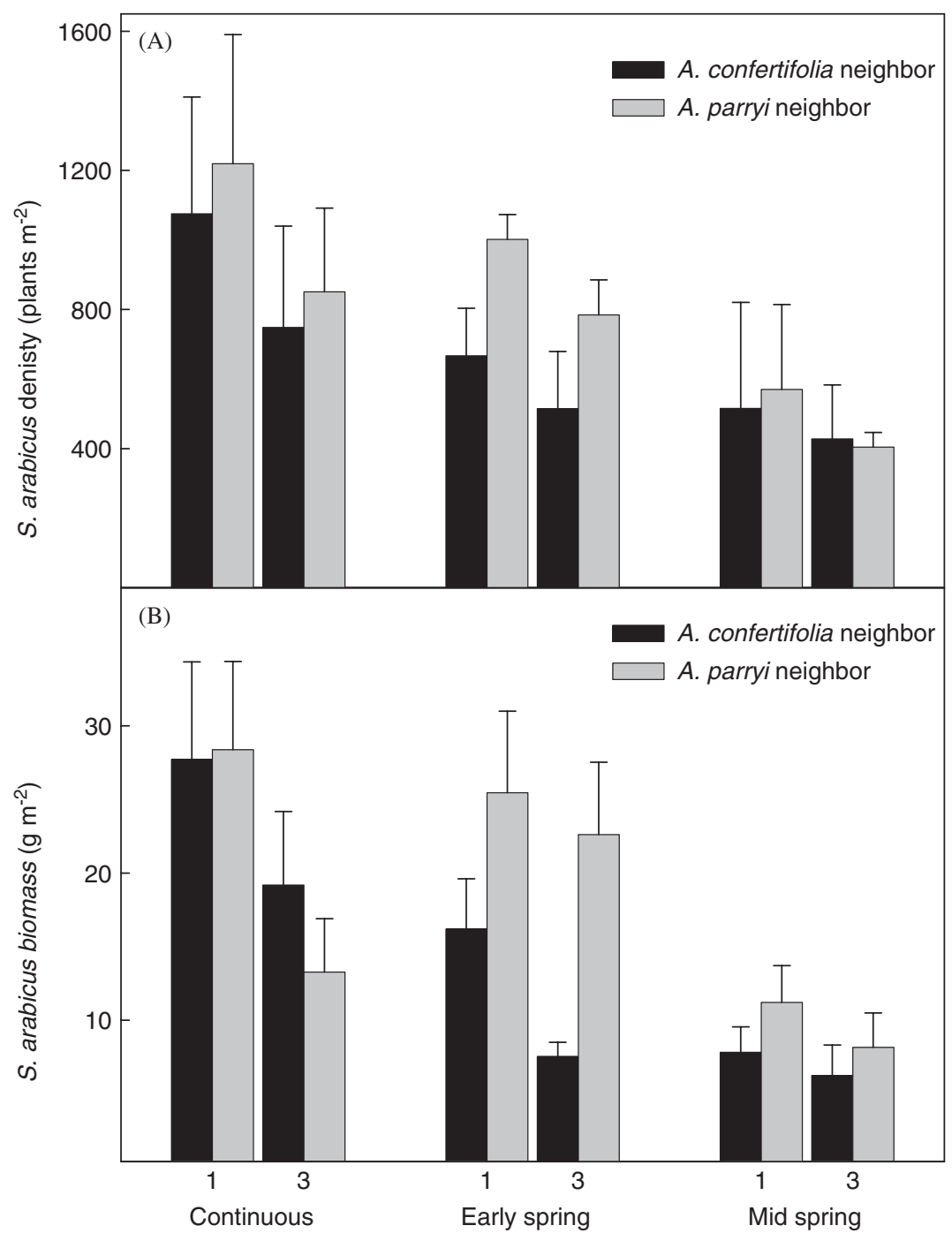

Fig. 1. Density (A) and biomass (B) of Schismus arabicus growing with either Atriplex confertifolia or Atriplex parryi neighbors planted at a density of one (1) or three (3) shrubs per plot (mean $\pm \mathrm{SE}, n=7$ ). Plots were assigned to receive water and $\mathrm{N}$ pulses either three times in early or mid spring or continuously throughout the growing season. The same amount of water and $\mathrm{N}$ was applied in all treatments. 
pulses, Schismus density $(P=0.0298)$ and biomass $(P=0.0046)$ was greater under continuous low resource supply as opposed to pulsed resource supply.

While the importance of resource pulses for growth, nutrient capture, and water relations of aridland plants has been demonstrated extensively (Bilbrough and Caldwell, 1997; BassiriRad et al., 1999; Gebauer and Ehleringer, 2000), there has been little effort placed on understanding how resource pulses may influence invasive plant establishment in arid systems. In this study, the effect of resource pulses on Schismus establishment was dependent on seasonal timing of resource pulses and identity of the neighbor shrub interacting with Schismus. As predicted by our first hypothesis, A. confertifolia had a greater ability to suppress Schismus than A. parryi when resources pulses occurred in early spring (Fig. 1a, b). In early spring, rates of root growth and nutrient capture by A. confertifolia at this site are up to 2 and 7 -fold greater than A. parryi, respectively (James, 2004). This suggests that higher rates of growth and resource capture by A. confertifolia in early spring resulted in lower amounts of unused resources following a pulse, which in turn suppressed Schismus establishment.

The corresponding hypothesis, however, that $A$. parryi would have a greater ability than A. confertifolia to suppress Schismus when resource pulses occurred in mid-spring was not supported. Following mid-spring pulses, Schismus density and biomass were comparable between the two shrubs (Fig. 1a,b). Schismus density with A. parryi neighbors, however, was on average 1.8-fold lower when resources pulses occurred in mid-spring relative to early spring. Part of this difference could be attributed to $A$. parryi more fully utilizing mid-spring pulses compared to early spring pulses. This decline also could be due to Schismus having lower germination rates, resource capture, and growth when resource pulses occurred later in the growing season or because of differences in evaporative demand between pulses. Previous research has shown that resource capture and growth of other invasive annual grasses, such as Bromus tectorum, decline when resource pulses occur later in the spring growing season (Bilbrough and Caldwell, 1997). In this experiment, Schismus density with $A$. confertifolia neighbors also was lower (ca. $20 \%$ ) following midspring pulses compared to early spring pulses. Together, these data suggest Schismus establishment was generally lower when resources pulses occurred in mid-spring, regardless of neighbor species.

The theory of fluctuating resource availability and habitat invasibility predicts that rapid increases in resource supply rates should make a plant community more susceptible to invasion (Davis et al., 2000). Thus, we predicted that regardless of neighbor plant identity, Schismus establishment would be greater when resources were pulsed relative to when equal resources were applied at a more continuous, low rate. Contrary to this prediction, density and biomass of Schismus was over 1.6-fold greater under continuous low resource supply as opposed to pulsed resource supply, when averaged across pulse and neighbor density treatments (Fig. 1a, b). In other work, water pulses compared to continuous water supply resulted in greater susceptibility to invasion in a perennial grass dominated old field (Davis and Peslor, 2001). In contrast, water and nutrient pulses applied in a montane grassland did not alter invasibility (Walker et al., 2005). Therefore, although few field studies have evaluated the effects of pulsed resource supply on invasibility results have been inconsistent and neither has shown increased invasibility with decreased fluctuations in resource supply.

Initially, our findings of greater establishment under more continuous resource supply appears to contradict the prediction proposed by Davis et al. (2000), but additional 
consideration of how soil resources may have been spatially distributed in the different resource pulse treatments suggests a potential alternative explanation. Namely, the small, frequent resource pulses applied in the continuous treatment likely infiltrated to a relatively shallow soil depth compared to the large resource pulses that were expected to wet the entire rooting zone (ca. $45 \mathrm{~cm}$ ). Because both Atriplex species maintain higher densities of active roots in deeper soil layers compared to shallow soil layers (Gebauer et al., 2002; James, 2004) the more shallowly rooted Schismus may have had greater access to resources in the continuous treatment compared to the pulse treatment. Spatial partitioning of resources between grasses and woody plants based on pulse size is widely thought to be a mechanism facilitating coexistence of grasses and woody plants (Weltzin and McPherson, 2000). If frequent small pulses in our experiment resulted in a more shallow distribution of resources compared to the pulse treatments, then there may have been a greater amount of unused resources by the native vegetation in the continuous treatment relative to the pulse treatment. Under these conditions the greater invasibility we observed in the continuous treatment would be consistent with the predictions of Davis et al. (2000).

Although some caution in interpreting these results is needed since this study was conducted at one site in 1 year, these initial findings suggest that the temporal dynamics of resources in arid systems has a strong potential to influence establishment of invasive annual grasses. Resources pulses that temporarily result in an increase in the amount of unused resources can facilitate invasive plant establishment. However, the effect of resource pulses depends strongly on when the pulse occurs in relation to growth rate and resource demand of the native vegetation. Because Schismus establishment was greater under smaller, frequent pulses, resource pulse magnitude and spatial distribution may be as important as seasonal timing in determining the invasibility in arid systems.

\section{Acknowledgments}

This research was supported by the CA State Lands Commission (C99017), Los Angeles Department of Water and Power and the California Agricultural Experiment Station.

\section{References}

BassiriRad, H., Tremmel, D.C., Virginia, R.A., Reynolds, J.F., de Soyza, A.G., Brunell, M.H., 1999. Short-term patterns in water and nitrogen acquisition by two desert shrubs following a simulated summer rain. Plant Ecology 145, 27-36.

Bilbrough, C.J., Caldwell, M.M., 1997. Exploitation of springtime ephemeral N pulses by six Great Basin plant species. Ecology 78, 231-243.

Breen, A.N., 2005. Improving seedling establishment on the saline playa at Owens Lake, California through soil amendment, improved seed quality, and increased seed entrapment. Ph.D. Dissertation, University of California, Davis, 116pp.

D’Antonio, C.M., Vitousek, P.M., 1992. Biological invasions by exotic grasses, the grass/fire cycle, and global change. Annual Review of Ecology and Systematics 23, 63-87.

Davis, M.A., Peslor, M., 2001. Experimental support for a resource-based mechanistic model of invasibility. Ecology Letters 4, 421-428.

Davis, M.A., Grime, J.P., Thompson, K., 2000. Fluctuating resources in plant communities: a general theory of invasibility. Journal of Ecology 88, 528-534.

Fisher, F.M., Parker, L.W., Anderson, J.P., Whitford, W.G., 1987. Nitrogen mineralization in a desert soilinteracting effects of soil moisture and nitrogen fertilizer. Soil Science Society of America Journal 51, $1033-1041$. 
Gebauer, R.L.E., Ehleringer, J.R., 2000. Water and nitrogen uptake patterns following moisture pulses in a cold desert community. Ecology 81, 1415-1424.

Gebauer, R.L.E., Schwinning, S., Ehleringer, J.R., 2002. Interspecific competition and resource pulse utilization in a cold desert community. Ecology 83, 2602-2616.

Goldberg, D., Novoplansky, A., 1997. On the relative importance of competition in unproductive environments. Journal of Ecology 85, 409-418.

Gutterman, Y., 2003. The inhibitory effect of Negev Desert loess soil on the fast germinating caryopses of Schismus arabicus (Poaceae). Journal of Arid Environments 54, 619-631.

James, J.J., 2004. Plant growth and physiological responses to soil resource heterogeneity in desert ecosystems. Ph.D. Dissertation. University of California, Davis, 114pp.

James, J.J., Richards, J.H., 2005. Plant N capture from pulses: effects of pulse size, growth rate, and other soil resources. Oecologia 145, 113-122.

Jeuffroy, M.H., Ney, B., Ourry, A., 2002. Integrated physiological and agronomic modeling of N capture and use within the plant. Journal of Experimental Botany 53, 809-823.

Johnson, H.B., Vasek, F.C., Yonkers, T., 1975. Productivity, diversity and stability relationship in Mojave Desert roadside vegetation. Bulletin of the Torrey Botanical Club 102, 106-115.

Loik, M.E., Breshears, D.D., Lauenroth, W.K., Belnap, J., 2004. A multi-scale perspective of water pulses in dryland ecosystems: climatology and ecohydrology of the western USA. Oecologia 141, 269-281.

Mack, R.N., 1984. Invasion of Bromus tectorum L. into western North America: an ecological chronicle. AgroEcosystems 7, 145-165.

Neter, J., Wasserman, W., Kutner, M.H., 1990. Applied Linear Statistical Models: Regression, Analysis of Variance, and Experimental Design, third ed. Irwin, Homewood.

Noy-Meir, I., 1973. Desert ecosystems: environments and producers. Annual Review of Ecology and Systematics 4, 25-51.

Nye, P., Tinker, P., 1977. Solute Movement in the Soil-root System. University of California Press, Berkeley.

SAS, 2001. SAS/STAT user's guide. Version 8. SAS Institute, Cary.

Shea, K., Chesson, P., 2002. Community ecology theory as a framework for biological invasions. Trends in Ecology \& Evolution 17, 170-176.

Stohlgren, T.J., Binkley, D., Chong, G.W., Kalkhan, M.A., Schell, L.D., Bull, K.A., Otsuki, Y., Newman, G., Baskin, M., Son, Y., 1999. Exotic species invade hot spots of native plant diversity. Ecological Monographs 69, 25-46.

Walker, S., Wilson, J.B., Lee, W.G., 2005. Does fluctuating resource availability increase invasibility? Evidence from field experiments in New Zealand short tussock grassland. Biological Invasions 7, 195-211.

Weltzin, J.F., McPherson, G.R., 2000. Implications of precipitation redistribution for shifts in temperate savanna ecotones. Ecology 81, 1902-1913. 